Published in final edited form as:

Mol Cell Endocrinol. 2007 September 30; 276(1-2): 1-9.

\title{
S179D Prolactin:
}

\section{Antagonistic Agony!}

\author{
Ameae M. Walker \\ Division of Biomedical Sciences, University of California, Riverside, Ca 92521
}

\begin{abstract}
The aims of this review are threefold: First, to collate what is known about the production and activities of phosphorylated prolactin (PRL), the latter largely, but not exclusively, as illustrated through the use of the molecular mimic, S179D PRL; second, to apply this and related knowledge to produce an updated model of prolactin-receptor interactions that may apply to other members of this cytokine super-family; and third, to promote a shift in the current paradigm for the development of clinically important growth antagonists. This third aim explains the title since, based on results with S179D PRL, it is proposed that agents which signal to antagonistic ends may be better therapeutics than pure antagonists - hence antagonistic agony. Since S179D PRL is not a pure antagonist, we have proposed the term selective prolactin receptor modulator (SPeRM) for this and like molecules.
\end{abstract}

\section{Phosphorylated PRL}

Phosphorylated PRL was described by the author's laboratory in 1986 (Oetting et al.). This first demonstration identified phosphorylated PRL as a normal product of pituitary mammotrophs and a normal constituent of standard pituitary extract preparations of PRL distributed by the Hormone and Pituitary Program of the United States National Institutes of Health. Since that time, phosphorylated PRL has been identified in all species examined, including cows (Brooks et al., 1990), sheep, chicken, turkeys (Aramburo et al., 1992), and humans (Tuazon et al., 2002; Wu et al., 2003). Both mono- and di-phosphorylated forms exist, but the mono-phosphorylated form is the most abundant (Oetting et al, 1986; Ho et al., 1993a;b;Wang and Walker,1993). The phosphorylation event producing the monophosphorylated form occurs on serine 177 in the rat sequence (Wang et al., 1996), which is equivalent to serine 179 in the human and bovine sequence. Direct analysis has shown phosphorylation of serine 179 in human PRL (Tuazon et al., 2002) and both serine 179 and 180 in the bovine sequence (Lorenson et al., 2000). Identification of the 177/179 phosphorylation site was complicated by the fact that trypsin digestion produces small, highly charged peptides in this region of PRL that even without phosphorylation pass straight through C18 columns (Wang et al., 1996) and hence are not included in routine analyses. It is for this reason that others have described an alternate major site of phosphorylation for the bovine hormone (Kim and Brooks, 1993).

\section{Biosynthesis}

PRL in the secretory granule is not posttranslationally modified and is packaged in a form with reduced osmotic activity by the formation of intermolecular disulfide bonds combined with divalent cation-stabilized ionic interactions (Lorenson, 1985;Martinez-Escalera et al.,

\footnotetext{
Publisher's Disclaimer: This is a PDF file of an unedited manuscript that has been accepted for publication. As a service to our customers we are providing this early version of the manuscript. The manuscript will undergo copyediting, typesetting, and review of the resulting proof before it is published in its final citable form. Please note that during the production process errors may be discovered which could affect the content, and all legal disclaimers that apply to the journal pertain.
} 
1986; Greenan et al., 1990; Lorenson et al., 1996a). Phosphorylation of PRL occurs in secretory granules just prior to/during exocytosis (Greenan et al., 1989,Wicks and Brooks, 1999). Phosphorylation appears to be tonically inhibited in the intact cell since granules must be isolated at low temperature to observe the storage form, and phosphorylation events can be followed simply by warming the granules to $37^{\circ} \mathrm{C}$ (Greenan et al., 1989). The mammotroph secretory granules contain the necessary ATP (Greenan et al., 1989, Lorenson et al., 1996b; Wicks and Brooks, 1999) and the kinase (a form of gamma p21 activated kinase (Tuazon et al., 2002)) required to achieve phosphorylation. Because phosphorylation occurs when the hormone is in the process of disulfide bond rearrangement (disulfide isomerase and glutathione are also present in the secretory granules (Lorenson and Jacobs, 1984;Greenan et al., 1990)) from the oligomeric to monomeric state, sites in the molecule that would normally be internal in the monomeric version of unmodified PRL are available to the kinase. Serine 179 is on the hydrophobic side of helix 4 and would therefore be in the hydrophobic core of monomeric unmodified PRL (Teilum et al., 2005). Thus, it is presumed that phosphorylation of serine 179 results in a different conformation than monomeric unmodified PRL (see below for work on the molecular mimic in this regard). Serine 177/179 is absolutely conserved among birds, amphibians and mammals, and the region around this serine is very highly conserved (Swiss protein database), making this a likely site for phosphorylation in many if not all species.

\section{Physiological regulation}

The degree of phosphorylation of PRL is physiologically regulated during the estrous cycle (Ho et al, 1993a), pseudopregnancy and pregnancy (Ho et al., 1993b), with periods of high estrogen decreasing the proportion phosphorylated. In addition, treatment of primary anterior pituitary cells with estrogen decreases phosphorylation (Liu and Walker, 1994), and treatment of rats with estrogen results in the coincident appearance of pituitary tumors and loss of PRL phosphorylation (Johnson et al., 2003). GH3 pituitary tumor cells do not normally phosphorylate PRL, but can be induced to do so by incubation in phosphorylated PRL (see later section including autoregulation) or by high concentrations of insulin (Ho et al., 1989). Phosphorylation coincides with the formation of initial secretory granules, although these immature secretory granules (Ho et al., 1989) do not coalesce to form the normal large granules of mammotrophs (Farquhar, 1977).

\section{Biological activity}

Dephosphorylation of highly purified pituitary extract PRL has been shown to increase the ability of that PRL to induce Nb2 cell proliferation, the modern measure of PRL bioactivity (Wang and Walker, 1993;Wicks and Brooks, 1995;Ellis and Picciano, 1995). Importantly, as illustrated in Wang and Walker (1993), removal of a small percentage of phosphorylated hormone resulted in a doubling of biological activity, a finding that indicated that phosphorylated PRL not only acted as an antagonist to the growth-promoting activity of unmodified PRL, but also that it did so when present at far less than equimolar amounts. GH3 pituitary tumor cells use unmodified PRL as an autocrine growth factor and addition of partially phosphorylated PRL (i.e. a proportion as normally extracted from the pituitary) inhibits cell proliferation (Krown et al., 1992). This is in addition to the induction of intracellular phosphorylation of endogenous PRL and the production of secretory granules described above. Phosphorylated PRL also acts as an autocrine inhibitor of further PRL release from primary pituitary cells in culture (an ultra short loop feedback mechanism), whereas unmodified PRL has a feed-forward loop (Ho et al., 1989;Krown et al., 1992;Johnson et al., 2003). Moreover, dephosphorylation of partially phosphorylated pituitary extract PRL stimulates GH3 cell proliferation (Krown et al., 1992). Dephosphorylation takes hours at high concentrations of phosphatase (Krown et al., 1992; Wang and Walker, 1993) and hence even though there is phosphatase activity in serum, phosphorylated PRL released from the pituitary has an 
opportunity to reach its target tissue intact. This phenomenon also suggests that the phosphate group is not very accessible to the enzyme.

\section{S179D PRL}

S179D PRL is a molecular mimic of mono-phosphorylated PRL in which the normally phosphorylated serine has been replaced by an aspartate residue. Initial examination showed this substitution to better mimic the phosphorylated form than a glutamate substitution (Chen et al., 1998). An aspartate residue mimics a phosphoserine both by its negative charge and by its space-filling properties. Analyses of several proteins, comparing the three-dimensional structure of an aspartate mutant with the phosphorylated form, have shown them to be extremely similar (Thorsness and Koshland, 1987). Also, this approach to the study of phosphoproteins has now become commonplace. S179D PRL was produced for a number of reasons. First, results with any extracted protein can always be criticized on the basis that there may be very small quantities of a contaminating highly bioactive compound that is producing the observed biological activity; second, the different biological activities of unmodified versus phosphorylated PRL could not be accurately documented and titrated until we could be sure that we did not have any phosphatase interconversion during the experiment; third, we could produce large quantities by recombinant techniques such that we could perform widespread in vivo analyses; and fourth, the growth antagonist properties lead us to consider the possibility that S179D PRL could be used as a clinical therapeutic. In addition, although we and others (Kim and Brooks, 1993) expended considerable energy on methods for the isolation of the different naturally phosphorylated forms, we were never satisfied with the quality of the preparations (discussed in Lorenson and Walker, 2001) and found them to have little advantage over the complete extract. Moreover, the expense of production of isolated phosphorylated forms excluded their use for in vivo analyses.

\section{S179D PRL inhibits cell proliferation}

Like the naturally phosphorylated form, the mimic inhibits unmodified PRL-stimulated proliferation of $\mathrm{Nb} 2$ cells when used at low concentrations and at low ratios with unmodified PRL (Wang and Walker,1993; Chen et al., 1998). However, when used alone and at high concentrations in cells that cannot activate alternate splicing of the receptor (see later), it shows some agonist activity, with about a two log increase in the amount required for equivalent activity to the unmodified hormone (Bernichtein et al., 2001;Soares et al., 2006). However, there is no circumstance in vivo when unmodified PRL is absent. S179D PRL also inhibits the proliferation of prostate cancer cells which use unmodified PRL as an autocrine growth factor (Xu et al., 2001). This inhibition can be titrated out by the addition of more unmodified PRL (Xu et al., 2001), showing competition between the two forms of PRL. S179D PRL also inhibits the growth of human prostate cancer xenografts in nude mice (Xu et al., 2001). The proliferation of breast cancer cells in response to unmodified PRL can also be inhibited by S179D PRL, and in cells from which the autocrine PRL has been knocked out, S179D PRL can be accurately titrated against unmodified PRL (Schroeder et al.,2003). Under these circumstances, S179D PRL has a marked effect at about one tenth the concentration of unmodified PRL (Schroeder et al., 2003). In vivo, S179D PRL inhibits the growth of the mammary gland during pregnancy in both rats and mice (Kuo et al.,2002;Naylor et al.,2005). In the normal mouse mammary cell line, HC11, S179D PRL inhibits the proliferation of actively growing cells (Wu et al., 2006) and unmodified PRL and S179D PRL have opposing effects on cell cycle regulatory proteins in contact-inhibited, differentiated cells (Wu et al., 2006). S179D PRL also inhibits the proliferation of human endothelial cells (Ueda et al.,2006a). In prostate, mammary, and endothelial cells, S179D PRL upregulates expression of the cell cycle regulatory protein, p21 (Wu et al., 2005; Wu et al., 2006; Ueda et al., 2006a). This is associated with upregulation of the vitamin $\mathrm{D}$ receptor, but the details of this association vary a little from one cell line to 
another. In prostate cancer cell lines, the vitamin $\mathrm{D}$ receptor appears to mediate all of the effect on p21 (Wu et al., 2007), whereas in HC11 cells, there also seem to be some vitamin D receptorindependent effects on p21 (Wu et al., 2006). In each case, blockade of ERK signaling inhibits the effect of S179D PRL on p21 (Wu et al., 2005;Wu et al., 2006; Ueda et al., 2006b).

\section{S179D PRL promotes differentiation}

In addition to inhibiting cell proliferation, S179D PRL also promotes cell-specific protein expression. This has been demonstrated both in vivo and in vitro. In vivo, S179D PRL increases the expression of prostate- or mammary-specific proteins such as probasin (Xu et al.,2002) or $\beta$-casein (Kuo et al.,2002), respectively. When analyzed in the HC11 cell line, the ability of S179D PRL to promote $\beta$-casein expression was found to be several fold greater than that of unmodified PRL and that the degree of difference between the two forms of PRL could be eliminated by incubation in a MAPK pathway inhibitor (Wu et al., 2003). The additional effect of S179D PRL is the result of both increased promoter activity and increased stability of $\beta$ casein mRNA (unpublished data). Increased promoter activity is also seen in T47D cells, but not in MCF7 cells (unpublished data). Thus the effect is cell context specific, a phenomenon recently described by Gutzman et al. for other elements of prolactin signaling (Gutzman et al., 2007). In vivo administration of S179D PRL also increases the expression of uncoupling proteins in brown fat (Budge et al., 2002;Pearce et al.,2005). Use of double aspartate mutants to mimic di-phosphorylated PRL showed equal ability to mono-phosphorylated PRL in the stimulation of $\beta$-casein expression (unpublished data).

\section{S179D PRL promotes apoptosis}

The system in which the effect of S179D PRL on apoptosis has been most thoroughly investigated to date is the human endothelial cell. In these cells, S179D PRL primarily uses the extrinsic pathway, although high concentrations and prolonged exposure can also secondarily activate the intrinsic pathway (Ueda et al., 2006b). Not only is S179D PRL proapoptotic in these cells, it can also overcome both the anti-apoptotic effects of several autocrine growth factors and the basic fibroblast growth factor (bFGF) which is present as an additive in the medium (Ueda et al., 2006b). Once again, the use of MAPkinase pathway inhibitors and a dominant negative ERK showed the involvement of ERK signaling in this effect of S179D PRL. Because of the sensitivity of endothelial cells to endotoxin and the fact that S179D PRL is made in bacteria, multiple endotoxin controls were run in all the experiments performed. In vivo, increased apoptosis is seen in Leydig cells of the testis in adult rats (submitted for publication), a result of which is decreased levels of circulating testosterone and dihydrotestosterone (Xu et al., 2002). No other normal tissues seem affected by treatment at this level (a dose that produces $\sim 50 \mathrm{ng} / \mathrm{ml}$ in the circulation) in adult animals, even if treatment is continued for one year. If S179D PRL is delivered to dams (at the same dose as for adult males) throughout pregnancy, the pups are born with increased apoptosis in the thymus and lungs (Yang et al.,2001). This was an unexpected result since one would have expected the very much higher concentrations of placental lactogens to swamp out any effect of S179D PRL. Part of this effect may have been due to the anti-angiogenic effect of S179D PRL (see next section), but since S179D PRL was also found in the circulation of newborn pups (Yang et al., 2001), it also appears that PRL receptors (PRLR) exhibit some selectivity for ligand.

\section{S179D PRL is anti-angiogenic}

S179D PRL, but not unmodified PRL, has been shown to be anti-angiogenic in the chick chorioallantoic membrane and corneal angiogenesis assays (Ueda et al., 2006a). Part of this effect is through decreased migratory and pseudotubule-forming activities of the endothelial cells, part by the down-regulation of endothelial expression of endogenous PRL, hemeoxygenase-1, bFGF, angiogenin, epidermal growth factor and vascular endothelial growth 
factor, and upregulation of the inhibitors of matrix metalloproteinases 1 and 2, and part through inhibition of signaling from bFGF (Ueda et al., 2006a,b). This anti-angiogenic activity likely contributes to in vivo effects on tumor growth, mammary growth and fetal development.

\section{S179D PRL is anti-inflammatory}

During the course of several in vivo studies, there were indications that S179D PRL was antiinflammatory. To test this in a readily quantifiable assay, the effect of S179D PRL on a delayed type hypersensitivity assay was determined. S179D PRL completely abrogated the response (Guzman et al., 2005). Analysis of peripheral immunoglobulin and cytokines in the local lymphnodes showed increased antibody levels to the precipitating antigen, but not an overall switch from $\mathrm{TH}_{1}$ to $\mathrm{TH}_{2}$ cytokines (Guzman et al., 2005). Instead, the cytokine changes could best be described as being consistent with reduced inflammation (Guzman et al., 2005). This general picture is consistent with previous observations in the NZB/NZW mouse model of lupus: When given S179D PRL, these animals lived longer but there was no reduction in circulating autoantibodies. Inflammatory pathology in the kidneys, however, was markedly reduced (Walker et al., 1999). More recently, we have determined that S179D PRL is able to block inflammation in the prostate, inflammation precipitated by the co-administration of estrogen and testosterone (unpublished data). Since inflammation contributes to the development and progression of cancer (Palapattu et al., 2005), and angiogenesis (Benelli et al., 2006), these anti-inflammatory activities could be a factor in anti-tumor activities in animals with an intact immune system.

\section{Testing of S179D PRL using in situ models of cancer}

Most animal models of cancer use promoters of tissue-specific genes to drive expression of transforming oncogenes. Given that S179D PRL promotes expression of tissue-specific genes (e.g. probasin), one can appreciate that such models are not appropriate for testing the antitumor activities of this molecule. However, the model of prostate cancer that recapitulates the loss of Pten observed in the human disease (Wang et al., 2003) is a viable possibility and testing in this model is scheduled to begin shortly. This will allow concomitant analysis of tumor development, angiogenesis, immune cell infiltration and local cytokines.

\section{Working hypothesis of the physiological role of phosphorylated PRL}

When phosphorylated PRL was first discovered, all we knew about its activities was that it antagonized the cell proliferation-promoting activities of unmodified PRL. From a biological standpoint, this could just as easily have been accomplished by the production of less unmodified hormone so the question was why would the pituitary expend energy phosphorylating the molecule? The answer we propose lies in the observations that S179D PRL promotes differentiation and apoptosis. Thus as illustrated in figure 1, we propose it is the balance between the two forms of PRL that dictates the end result: At one extreme unmodified PRL goes unchecked, resulting in abnormal cell proliferation and tumor formation. This is followed by a balance with a small amount of phosphorylated PRL which allows normal tissue proliferation. With increasing proportions of phosphorylated PRL would come differentiation, but this would still allow for normal tissue cell replacement. At the other extreme, high proportions of phosphorylated PRL would promote apoptosis, at least in cells capable of alternative splicing of the receptor.

\section{Ligand-Receptor Interactions}

The sequence of events involved in full length PRLR signaling has been described as follows: 1) the binding of PRL to one receptor, 2) the recruitment of a second receptor to form a ternary complex, 3) transphosphorylation of receptor-associated janus kinase (Jak) molecules due to their new proximity, 4) tyrosine phosphorylation of the receptor by this activated Jak, 5) the 
recruitment of signal transducer and activator of transcription (Stat) to the site of phosphorylation on the receptor and Stat's subsequent tyrosine phosphorylation by Jak, and 6) dissociation of the phosphorylated Stats from the receptors, their dimerization and transport into the nucleus (figure 2, sections 1 and 2).

Use of phosphorylated PRL/S179D PRL has allowed us to learn a great deal more about how ligands interact with the PRL receptor (PRLR). When first identified as an antagonist to unmodified PRL, we knew that both forms interacted with the same receptor type since $\mathrm{Nb} 2$ cells only express one form of the receptor (Ali et al., 1991). Thus, one could envisage phosphorylated/S179D PRL simply blocking the effect of unmodified PRL by occupying a receptor, but not inducing a signal. However, as mentioned above, small proportions of phosphorylated PRL/S179D PRL as low as 6-10\% have significant effects on cell proliferation (Wang and Walker,1993,Schroeder et al.,2003), Stat 5 activation (Coss et al.,1999;Wu et al., 2003;Schroeder et al.,2003), and signaling leading to activation of cyclin D1 (Schroeder et al., 2003; Wu et al., 2006). This, as several leading investigators said at the time of our original presentation of this finding, is impossible! Their statement was based on the accepted model of PRLR signaling described above. This model suggested that the simple act of bringing two PRLRs together initiated a Jak-Stat signal, and that production of an antagonist required a molecule that bound one receptor and was unable to recruit a second. With this model, 6-10\% phosphorylated/S179D PRL could not occupy enough receptors to antagonize $90 \%$ unmodified PRL - but antagonism is what occurred. Also suggested by some was the possibility that S179D PRL bound to another receptor altogether. Using $\beta$-casein-luciferase constructs transfected into HEK 293 cells, we found no ability of S179D PRL to activate this promoter until PRLR were co-transfected (Tan et al., 2005). Since so many cell types express the PRLR, it is difficult to be as definitive in other cell types. However, by setting analysis at a level only responsive to transfected levels of the receptor, or by transfecting a different form of the receptor to that normally expressed, we have been able to draw the same conclusion for prostate cancer $(\mathrm{Wu}$ et al., 2005) and other cell types. Using luciferase- and green fluorescent protein-tagged receptors, it was also possible to demonstrate that each PRL (i.e. unmodified or S179D) was functional with the same receptor homo- and hetero-pairs in terms of bringing the signaling regions close enough to initiate signaling (Tan et al., 2005).

\section{Different signaling with unmodified versus S179D PRL}

It seems fairly clear therefore that S179D PRL interacts with the same receptors as unmodified PRL. How then could there be a different end result of that interaction and how could relatively small proportions of S179D PRL be disproportionately active? To analyze this question, we examined signaling signatures when each PRL was used alone and in combination. This work focused on the two well-studied signaling pathways and is best illustrated by work with HC11 cells. These two pathways are Jak2-Stat5 (described above) and an alternate cascade that activates ERK 1/2. Although both forms of PRL activated both pathways to some extent, unmodified PRL predominantly activated Jak2-Stat5 and S179D PRL predominantly activated ERK 1/2 (Wu et al., 2003). In addition, S179D PRL inhibited Stat5 activation in response to unmodified PRL when both were used together (Wu et al., 2003). This latter is also well illustrated in Nb2 cells (Coss et al.,1999) and MCF7 cells (Schroeder et al.,2003). In addition, partially phosphorylated PRL (i.e. pituitary extract) showed signaling in between unmodified PRL and S179D PRL, as would be predicted (Coss et al., 1999; Wu et al., 2003). These differences in signaling occurred in cells that up to the initiation of signaling had been treated identically and therefore had the same complement of receptors. Continued exposure to S179D PRL, however, alters splicing to increase expression of short receptors (Wu et al., 2003; Wu et al., 2005; Ueda et al, 2006a). Thus, while signaling is different with the same complement of receptors, long term exposure amplifies the difference in signaling by altering the production of different forms of the receptor. With the exception of $\mathrm{Nb} 2$ and MCF7 cells, all other 
naturally-occurring cell types examined to date upregulate a short form of the receptor in response to S179D PRL. This is well illustrated by human endothelial cells (Ueda et al, 2006a) and prostate cancer cells (Wu et al., 2005). These short forms of the PRLR activate ERK 1/2 in response to S179D PRL (Wu et al., 2005; Ueda et al, 2006a;b).

\section{How might a different signal be initiated?}

How then does S179D PRL activate a different signal when only one type of receptor, or the same complement of receptors, is present? A potential clue here is offered by work from several other laboratories. First, it seems that growth hormone receptors, erythropoietin receptors and PRLRs are all dimerized prior to ligand binding (Brown et al., 2005;Lu et al., 2006; Qazi et al., 2006). This has long seemed more likely to the author (Kuo et al., 1998) since waiting for random collision of the second receptor with the complex between ligand and first receptor seemed inefficient. Contrary to some reports, our own work in this regard does not contradict these findings, since BRET studies from the author's laboratory were aimed at determining what happened upon ligand binding and hence used linkers in the construction of the tagged receptors such that no BRET signal was generated until ligand binding (Tan et al., 2005). But importantly, what predimerization now tells us is that if the receptors are predimerized, the receptor must undergo a conformational change upon ligand binding, a change that is transmitted through the transmembrane region to the intracellular domain, resulting in the closer approximation of the receptor-associated Jak molecules. This was an idea voiced years ago and disregarded because the transmembrane domain was thought to be too flexible to adequately transmit information. This however, was when flexing of the cytoplasmic domain was imagined. Instead, as previously illustrated (Walker, 2005) and as shown in figure 2, rotation of the receptor may well be the key. The potential for such a scenario is supported by some elegant work using the erythropoietin receptor (Seubert et al., 2003) and, more recently using the growth hormone receptor (Brown et al., 2005). Each study showed a one amino acid twist in the transmembrane helical region of the receptor to produce altered signaling. In the case of the erythropoietin receptor, different degrees of rotation produced altered ratios of Jak2Stat5 to ERK 1/2 signaling (Seubert et al., 2003), just as we see for unmodified PRL versus S179D PRL. Also, a naturally-occurring variant of growth hormone with a one amino acid substitution has altered signaling at the receptor (Lewis et al., 2004).

\section{The new model}

Thus, added to the concept of altered relative proximity of the signaling regions in response to ligand is the idea that different ligands may produce a somewhat different degree of rotation/ angle of rotation than others, thereby resulting in the generation of different signals. This is illustrated very simplistically in figure 2 for unmodified PRL versus S179D PRL. As illustrated, rotation occurs in response to the binding of the second receptor. Because S179D PRL is predicted to have an altered conformation, it is suggested that rotation with this ligand additionally results in blockade of the Stat 5 binding site on the receptor and a closer approximation of Jak2 (J) with a complex of adapter and signaling molecules upstream of ERK (A). Carrying this idea further, is the notion that interaction of the placental lactogens or zinccoordinated growth hormone with the PRLR may also produce a somewhat different signaling signature. For the sake of simplicity, we have only discussed two of the signaling pathways, but there are a large number of pathways activated at the PRLR (Clevenger et al., 2001) which may play a role in distinguishing the end effect of different ligands.

\section{Conformation of S179D PRL}

What is the evidence that S179D PRL has a different conformation from unmodified PRL? First, we go back to statements made earlier that energetically it is unlikely for a phosphate or aspartate to sit comfortably inside the hydrophobic core of the molecule. It is likely that 
minimally there is a twist in helix 4 compared to unmodified PRL. Serine 179 is a surprisingly crucial residue to the structure of PRL since its mutation to alanine eliminates biological activity of otherwise unmodified PRL (Chen et al., 1998;Kato et al., 1996). Also, mutational analyses of amino acids on the outside of the helix in this region have shown the region to be important in regulating PRL-receptor interactions (Kinet et al., 1996). Second, even polyclonal antibodies against PRL recognize S179D PRL as somewhat different from unmodified PRL (Chen et al., 1998). Third, S179D PRL has a number of altered physical properties which include, a decrease in hydrophobicity consistent with the addition of more than one negative charge versus the unmodified hormone (Soares et al.,2006), an increased ability to bind heparin, and an inability to bind to nickel (unpublished data). These latter two determinations were exactly the opposite of what one would have predicted from an additional negative charge. In the study where this was determined, the S179D PRL was also produced in mammalian cells and therefore had passed all of the cell's quality control measures for proper folding. It therefore appears that S179D PRL has a different conformation and that its interaction with a pair of PRLRs may produce a different conformation in them. This altered conformation versus unmodified PRL may well be subtle since based on the work with the erythropoietin receptor, an approximately one amino acid turn in the transmembrane domain would be sufficient to alter signaling from primarily Jak-Stat to primarily ERK (Seubert et al., 2003). As cartooned in figure 2, the long PRLR responds differently to the two forms of PRL and this difference is amplified once the short PRLRs are upregulated by the promotion of alternative splicing. Since the short receptors cannot efficiently activate Stat 5 (they are missing the tyrosine on the receptor which serves as a docking site) signaling via ERK increases with time. Also cartooned in figure 2 is how ERK activation may increase $\beta$-casein gene expression. Certainly, S179D PRL results in increased serine phosphorylation of Stat 5 (Wu et al., 2003). Increased serine phosphorylation of other Stats results in longer half life on DNA (Zhang et al., 1995) and therefore increased promoter activation. However, ERK mediation of serine phosphorylation on Stat 5 is disputed (Wartmann et al., 1996; Yamashita et al., 1998). Additionally, S179D PRL increases the half life of $\beta$-casein mRNA (cartooned as the phosphorylation of a protein bound to the poly A tail of the mRNA), but the mechanism of this remains to be determined. In addition, the cartoon illustrates how signaling elements from the receptor engaged by S179D PRL (dark green triangles) form a cascade which reduces Stat 5 tyrosine phosphorylation and hence how a small proportion of S179D PRL could affect a much larger proportion of unmodified PRL. It is also proposed that largely tyrosine phosphorylated Stat 5 is responsible for cell cycle progression (cyclin mRNA) and that other ERK phosphorylated transcription factors (blue hexagon) contribute to inhibition of the cell cycle (p21 mRNA).

\section{Association of ERK activation with cell differentiation and apoptosis}

Activation of ERK by S179D PRL at the short receptor is slow and sustained (Wu et al., 2005; Ueda et al., 2006b), a mode of activation also shown in other systems to promote differentiation (Suzu et al., 2007), limit cell proliferation (Tombes et al., 1998), and promote apoptosis (Zheng et al., 2007) and not cell proliferation. In fact, S179D PRL inhibits the immediate and transient activation of ERK by bFGF (Ueda et al., 1996b).

\section{Antagonistic agony}

S179D PRL is therefore an agonist for differentiation, cell cycle control and apoptosis and an antagonist for cell proliferation. Inhibition of the growth-promoting signal, together with the production of an alternate amplifying signal cascade resulting in cell cycle control, is what allows S179D PRL to effectively modulate the function of unmodified PRL at such low relative concentrations. In the search for growth antagonists for the control of abnormal cell proliferation therefore, it is proposed that a molecule that signals to antagonism is likely to be more efficacious than one that merely blocks binding of an agonist to the receptor. 


\section{Acknowledgements}

The author would like to thank all of the wonderful people who have worked in the lab over the years, the many collaborators whose work has strengthened the developing story about S179D PRL, and the granting agencies that have supported the work. Recent work in the laboratory has been supported by NIH grant DK 61005, California Breast Cancer Research Program grant 10PB0127, Department of Defense Breast Cancer Program grant BC051103, and a grant from the Prostate Cancer Foundation.

\section{References}

Ali S, Pelligrini I, Kelly PA. A prolactin-dependent immune cell line (Nb2) expresses a mutant form of prolactin receptor. J. Biol. Chem 1991;266:20110-20117. [PubMed: 1718958]

Aramburo C, Montiel JL, Proudman JA, Berghman LR, Scanes CG. Phosphorylation of PRL and growth hormone. J. Mol. Endocrinol 1992;8:183-191. [PubMed: 1632894]

Benelli R, Lorusso G, Albini A, Noonan DM. Cytokines and chemokines as regulators of angiogenesis in health and disease. Curr. Pharm. Des 2006;12:3101-3115. [PubMed: 16918437]

Bernichtein S, Kinet S, Jeay S, Llovera M, Madern D, Martial JA, Kelly PA, Goffin V. S179D-human PRL, a pseudophosphorylated human PRL analog, is an agonist and not an antagonist. Endocrinology 2001;142:3950-3963. [PubMed: 11517174]

Brooks CL, Kim BG, Aphale P, Kleeman BE, Johnson GC. Phosphorylated variant of bovine prolactin. Mol. Cell. Endocrinol 1990;71:117-123. [PubMed: 2376284]

Brown RJ, Adams JJ, Pelekanos RA, Wan Y, McKinstry WJ, Palethorpe K, Seeber RM, Monks TA, Eidne KA, Parker MW, Waters MJ. Model for growth hormone receptor activation based on subunit rotation within a receptor dimer. Nat. Strct. Biol 2005;12:814-821.

Budge H, Mostyn A, Wilson V, Khong A, Walker AM, Symonds ME, Stephenson T. The effect of maternal prolactin infusion during pregnancy on fetal adipose tissue development. J. Endocrinol 2002;174:427-433. [PubMed: 12208663]

Chen TJ, Kuo C-YB, Tsai KF, Liu J-W, Chen D-Y, Walker AM. Development of recombinant human prolactin receptor antagonists by molecular mimicry of the phosphorylated hormone. Endocrinology 1998;139:609-616. [PubMed: 9449632]

Clevenger, CV.; Rycyzyn, MA.; Syed, F.; Kline, JB. Prolactin receptor signal transduction. In: Horseman, ND., editor. Prolactin. Kluwer Academic Press; Massachusetts: 2001. p. 355-379.

Ellis LA, Picciano MF. Bioactive and immunoreactive prolactin variants in human milk. Endocrinology 1995;136:2711-2720. [PubMed: 7750496]

Farquhar MG. Secretion and crinophagy in prolactin cells. Adv. Exp. Med. Biol 1977;80:37-94. [PubMed: 70981]

Greenan JR, Balden E, Ho TWC, Walker AM. Biosynthesis of the secreted 24 kd isoforms of prolactin. Endocrinology 1989;125:2041-2048. [PubMed: 2791977]

Greenan JR, Lorenson MY, Conconi MV, Walker AM. Alterations in in Situ prolactin secretory granule morphology and immunoactivity by thiols and divalent cations. Endocrinology 1990;126:512-518. [PubMed: 2294001]

GutzmanJ,HRugowskiD,ENikolaiS,ESchulerL,A2007 Stat 5 activation inhibits prolactin-induced AP1 activity:distinct prolactin-initiated signals in tumorigenesis dependent on cell context. Oncogene April 16th E pub ahead of print

Guzman EA, Chen YH, Langowski JL, De Guzman A, Lo H-L, Walter B, Muller HK, Walker AM, Owen LB. Abrogation of Delayed Type Hypersensitivity Responses to Candida Albicans Produced by a Molecular Mimic of Phosphorylated Prolactin. J. Neuroimmunology 2005;170:31-40. [PubMed: 16169603]

Ho TWC, Greenan JR, Walker AM. Mammotroph autoregulation: The differential roles of the $24 \mathrm{Kd}$ isoforms of prolactin. Endocrinology 1989;124:1507-1514. [PubMed: 2917523]

Ho TWC, Leong F-S, Olaso CH, Walker AM. Secretion of specific non-phosphorylated and phosphorylated rat prolactin isoforms at different stages of the estrous cycle. Neuroendocrinology 1993;58:160-165. [PubMed: 8264862]

Ho TWC, Kawaminami M, Walker AM. Secretion of phosphorylated and non-phosphorylated monomer prolactin isoforms during rat pregnancy and pseudopregnancy. Endocrine J 1993;1:435-439. 
Johnson TE, Vue M, Brekhus S, Khong A, Ho TWC, Walker AM. Unmodified prolactin (PRL) promotes PRL secretion and acidophil hypertrophy and is associated with pituitary hyperplasia in female rats. Endocrine (special edition on prolactin) 2003;20:101-110.

Kato Y, Maruyama O, Chung HO, Tomizawa K, Kato T. Amino acids in highly conserved regions near the C-terminus of rat prolactin (PRL) play critical roles similar to those in binding of human GH to the PRL receptor. Biochem. Biophys. Res. Commun 1996;222:547-552. [PubMed: 8670242]

Kim BG, Brooks CL. Isolation and characterization of phosphorylated bovine prolactin. Biochem. J 1993;296:41-47. [PubMed: 8250856]

Kinet S, Goffin V, Mainfroid V, Matial JA. Characterization of lactogen receptor-binding site 1 of human prolactin. J. Biol. Chem 1996;271:14353-14360. [PubMed: 8662911]

Krown KA, Wang Y-F, Ho TWC, Kelly PA, Walker AM. Prolactin isoform 2 as an autocrine growth factor for $\mathrm{GH}_{3}$ cells. Endocrinology 1992;131:595-602. [PubMed: 1639009]

Kuo C-YB, Coss D, Walker AM. Prolactin receptor antagonists. Endocrine 1998;9:121-131. [PubMed: 9867245]

Kuo CB, Wu W, Xu X, Yang L, Chen C, Coss D, Birdsall B, Nasseri D, Walker AM. Pseudophosphorylated prolactin (S179D PRL) inhibits growth and promotes beta-casein gene expression in the rat mammary gland. Cell Tissue Res 2002;309:429-437. [PubMed: 12195299]

Lewis MD, Horan M, Millar DS, Newsway V, Easter TE, Frykland L, Gregory JW, Norin M, Del Valle CJ, Lopez-Siguero JP, Canete R, Lopez-Canti LF, Diaz-Torrado N, Espino R, Ulied A, Scanlon MF, Procter AM, Cooper DN. A novel dysfunctional growth hormone variant (Ile179Met) exhibits a decreased ability to activate the extracellular signal-regulated kinase pathway. J. Clin. Endocrinol. Metab 2004;89:1068-1075. [PubMed: 15001589]

LiuJ,-WWalkerA,MLong term effect of estradiol and thyrotropin releasing hormone on the release of non-phosphorylated and phosphorylated monomer PRL in vitro76th annual meeting of the Endocrine SocietyAnaheim, California1994 (Abstract)

Lorenson MY. In vitro conditions modify immunoassayability of bovine pituitary prolactin and growth hormone:insights into their secretory granule storage forms. Endocrinology 1985;116:1399-1407. [PubMed: 3918853]

Lorenson MY, Jacobs LS. Depletion of bovine pituitary prolactin by cysteamine involves thiol:disulfide mechanism. Endocrinology 1984;115:1492-1495. [PubMed: 6479100]

Lorenson MY, Patel T, Liu J-W, Walker AM. Prolactin (PRL) is a zinc binding protein I. Zinc interactions with monomeric PRL and divalent cation protection of intragranular PRL cysteine thiols. Endocrinology 1996;137:809-816. [PubMed: 8603589]

Lorenson MY, Liu M-W, Patel T, Walker AM. Intragranular prolactin phosphorylation and kallikrein cleavage are regulated by zinc and other divalent cations. Endocrine 1996;4:244-257.

LorensonMYTuazonPTTraughJAWalkerAMP21-activated protein kinase $(\gamma$-PAK) is present in rat and bovine prolactin (PRL) secretory granules and can phosphorylate PRL on the serine crucial to biological activity2000Endocrine Society 82nd annual meetingToronto, CanadaJune (Abstract)

Lorenson, MY.; Walker, AM. Structure-function relationships in prolactin. In: Horseman, ND., editor. Prolactin. Kluwer Academic Publishers; Massachusetts: 2001. p. 189-217.

Lu X, Gross AW, Lodish HF. Active conformation of the erythropoietin receptor: random and cysteinescanning mutagenesis of the extracellular juxtamembrane and transmembrane domains. J. Biol. Chem 2006;281:7002-7011. [PubMed: 16414957]

Martinez-Escalera G, Clapp C, Morales MT, Lorenson MY, Menam F. Reversal by thiols of dopamine-, stalk-median eminence-, and zinc-induced inhibition of prolactin transformation in adenohypophyses of lactating rats. Endocrinology 1986;118:1803-1807. [PubMed: 3698896]

Naylor MJ, Oakes SR, Gardiner-Garden M, Harris J, Blazek K, Ho TWC, Li FC, Wynick D, Walker AM, Ormandy CJ. Transcriptional changes underlying the secretory activation phase of mammary gland development. Mol. Endocrinol 2005;19:1868-1883. [PubMed: 15705664]

Oetting WS, Tuazon PT, Traugh JA, Walker AM. Phosphorylation of prolactin. J. Biol. Chem 1986;261:1649-1652. [PubMed: 3003080]

Palapattu GS, Sutcliffe S, Bastian PJ, Platz EA, De Marzo AM, Isaccs WB, Nelson WG. Prostate carcinogenesis and inflammation: emerging insights. Carcinogenesis 2005;26:1170-1181. [PubMed: 15498784] 
Pearce S, Budge H, Mostyn A, Generver E, Webb R, Ingleton P, Walker AM, Symonds ME, Stephenson T. Prolactin, the prolactin receptor and uncoupling protein abundance and function in adipose tissue during development in young sheep. J. Endocrinol 2005;184:351-359. [PubMed: 15684343]

Qazi AM, Tsai-Morris CH, Dufau ML. Ligand-independent hono- and heterodimerization of human prolactin receptor variants:inhibitory action of the short forms by heterodimerization. Mol. Endocrinol 2006;20:1912-1923. [PubMed: 16556730]

Schroeder MD, Brockman JL, Walker AM, Schuler LA. Inhibition of prolactin (PRL)-induced proliferative signals in breast cancer cells by a molecular mimic of phosphorylated PRL, S179D PRL. Endocrinology 2003;144:5300-5307. [PubMed: 12970160]

Seubert N, Royer Y, Staerk J, Kubatzky KF, Moucadel V, Krishnakumar S, Smith SO, Constantinescu $\mathrm{SN}$. Active and inactive orientations of the transmembrane and cytosolic domains of the erythropoietin receptor dimer. Mol. Cell 2003;12:1239-1250. [PubMed: 14636581]

Soares CRJ, Glezer A, Okazaki K, Ueda EKM, Heller SR, Walker AM, Goffin V, Bartolini P. Physicochemical and biological characterizations of two human prolactin analogs exhibiting controversial bioactivity, synthesized in Chinese hamster ovary $(\mathrm{CHO})$ cells. Protein Expression and Purification 2006;48:182-194. [PubMed: 16814566]

SuzuSHiyoshiMYoshidomiYHaradaHTakeyaMKimuraFMotoyoshiKOkadaSM-CSF-mediated macrophage differentiation but not proliferation is correlated with increased and prolonged ERK activation. J. Cell. Physiol2007 April 18th E pub ahead of print

Teilum K, Hoch JC, Goffin V, Kinet S, Martial JA, Kragelund BB. Solution structure of human prolactin. J. Mol. Biol 2005;351:810-823. [PubMed: 16045928]

Thorsness PE, Koshland DE Jr. Inactivation of isocitrate dehydrogenase by phosphorylation is mediated by the negative charge of the phosphate. J. Biol. Chem 1987;262:422-425.

Tombes RM, Auer KL, Mikkelsen R, Valerie K, Wymann MP, Marshall CJ, McMahon M, Dent P. The mitogen-activated protein (MAP) kinase cascade can either stimulate of inhibit DNA synthesis in primary cultures of rat hepatocytes depending upon whether its activation is acute/phasic or chronic. Biochem. J 1998;330:1451-1460. [PubMed: 9494119]

Tuazon PT, Lorenson MY, Walker AM, Traugh JA. p21-activated protein kinase gamma-PAK in pituitary secretory granules phosphorylates prolactin. FEBS Lett 2002;515:84-88. [PubMed: 11943200]

Ueda E, Ozerdem U, Chen YH, Yao M, Huang KT, Sun H, Martins-Green M, Bartolini P, Walker AM. A molecular mimic demonstrates that phosphorylated human prolactin is a potent anti-angiogenic hormone. Endocrine Related Cancer 2006;13:95-111. [PubMed: 16601282]

Ueda E, Lo H-L, Bartolini P, Walker AM. S179D prolactin (PRL) primarily uses the extrinsic pathway and MAPkinase signaling to induce apoptosis in human endothelial cells. Endocrinology 2006;147:4627-4637. [PubMed: 16840547]

Walker, SE.; Yang, L.; Kuo, B.; Walker, AM. A pilot study suggests that prolactin shortens and a prolactin receptor antagonist lebgthens, the life span of NZB/NZW mice with spontaneous lupus erythematosus; 81st Annual meeting of the Endocrine Society; San Diego. 1999;

Walker AM. Prolactin Receptor Antagonists. Current Opin Investigational Drugs 2005;6:378-385.

Wang Y-F, Walker AM. Dephosphorylation of standard prolactin produces a more biologically active molecule. Evidence for antagonism between non-phosphorylated and phosphorylated prolactin in the stimulation of Nb2 cell proliferation. Endocrinology 1993;133:2156-2160. [PubMed: 8404666]

Wang Y-F, Liu J-W, Mamidi M, Walker AM. Identification of the major site of rat prolactin phosphorylation as serine 177. J. Biol. Chem 1996;271:2462-2469. [PubMed: 8576208]

Wang S, Gao J, Lei Q, Rozengurt N, Pritchard C, Jiao J, Thomas GV, Li G, Roy-Burman P, Nelson PS, Liu X, Wu H. Prostate-specific deletion of the murine Pten tumor suppressor gene leads to metastatic prostate cancer. Cancer Cell 2003;4:209-221. [PubMed: 14522255]

Wartmann M, Cella N, Hofer P, Groner B, Liu X, Hennighausen L, Hynes NE. Lactogenic hormone activation of Stat 5 and transcription of the $\beta$-casein gene in mammary epithelial cells is independent of p42 ERK2 mitogen-activated protein kinase activity. J. Biol. Chem 1996;271:31863-31868. [PubMed: 8943229]

Wicks JR, Brooks CL. Prolactin kinase activity in bovine anterior pituitary sub-cellular fractions. Mol. Cell. Endocrinol 1999;147:125-132. [PubMed: 10195699] 
Wicks JR, Brooks CL. Biological activity of phosphorylated and dephosphorylated bovine prolactins. Mol. Cell. Endocrinol 1995;112:223-229. [PubMed: 7489826]

Wu W, Coss D, Lorenson MY, Kuo CB, Xu X, Walker AM. Different Biological Effects of unmodified prolactin and a molecular mimic of phosphorylated prolactin involve different signaling pathways. Biochemistry 2003;42:7561-7570. [PubMed: 12809512]

Wu W, Ginsburg E, Vonderhaar BK, Walker AM. S179D prolactin increases vitamin D receptor and $\mathrm{p} 21$ through upregulation of short $1 \mathrm{~b}$ prolactin receptor in human prostate cancer cells. Cancer Research 2005;65:7509-7515. [PubMed: 16103106]

Wu W, Chen YH, Ueda E, Tan D, Bartolini P, Walker AM. Different forms of prolactin have opposing effects on the expression of cell cycle regulatory proteins in differentiated mammary epithelial cells. Oncology Research 2006;16:75-84. [PubMed: 16898268]

WuWZanelloLWalkerAMS179D Prolactin Sensitizes Human Prostate Cancer Cells such that Physiological Concentrations of 1, 25 dihydroxy Vitamin D 3 result in Growth Inhibition and Cell Death. Prostate2007 in press

Xu X, Kreye E, Kuo CB, Walker AM. A molecular mimic of phosphorylated prolactin markedly reduced tumor incidence and size when DU145 human prostate cancer cells were grown in nude mice. Cancer Res 2001;61:6098-6114. [PubMed: 11507059]

Xu X, Wu W, Williams V, Khong A, Chen Y-H, Deng C, Walker AM. Opposite effects of unmodified prolactin on morphology and the expression of prostate-specific genes in the normal rat prostate. Prostate 2002;54:1-9.

Yamashita H, Xu J, Erwin RA, Farrar WL, Kirken RA, Rui H. Differential control of the phosphorylation state of proline-juxtaposed serine residues Ser 725 of Stat 5a and Ser 730 of Stat $5 b$ in prolactinsensitive cells. J. Biol. Chem 1998;273:30218-30224. [PubMed: 9804779]

Yang L, Kuo CB, Liu Y, Coss D, Xu X, Chen C, Oster-Granite ML, Walker AM. Administration of unmodified prolactin (U-PRL) and a molecular mimic of phosphorylated prolactin (PP-PRL) during rat pregnancy provides evidence that the U-PRL:PP-PRL ratio is crucial to the normal development of pup tissues. J. Endocrinol 2001;168:227-238. [PubMed: 11182760]

Zhang JJ, Blenis J, Li HC, Schindler C, Chen-Kiang S. Requirement of serine phosphorylation for formation of Stat-promoter complexes. Science 1995;267:1990-1994. [PubMed: 7701321]

ZhengAKallioAHarkonenPTamoxifen-induced rapid death of MCF-7 breast cancer cells is mediated via ERK signaling and can be abrogated by estrogen. Endocrinology2007 March 15th E pub ahead of print 


\section{Abnormal Normal Differentiation proliferation}

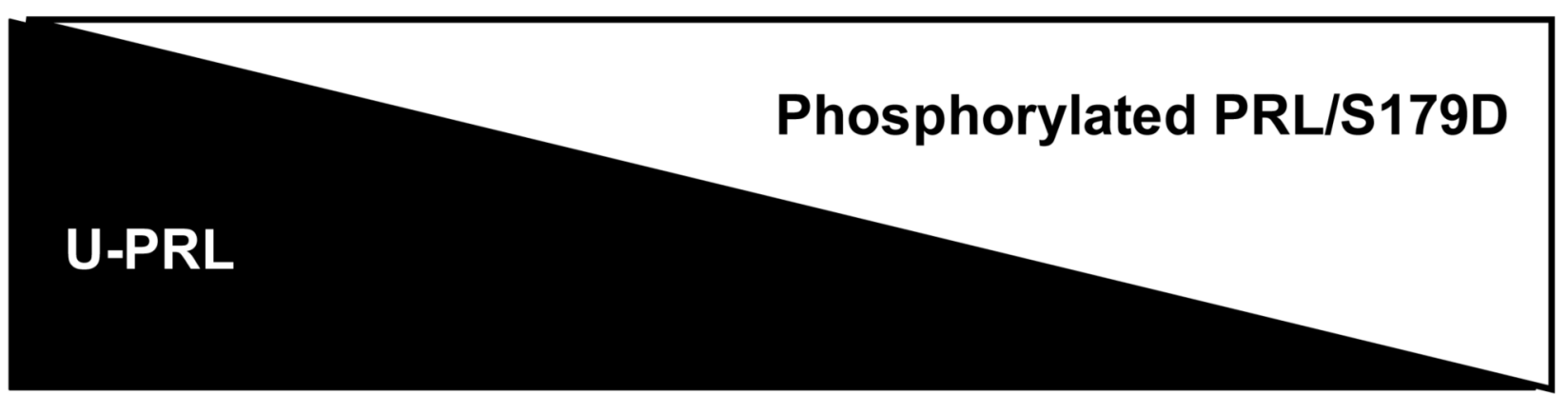

Figure 1. Diagrammatic Representation of the Proposed Properties of Different Ratios of Unmodified and Phosphorylated/S179D PRL

At one extreme, the presence of only unmodified PRL results in excess cell proliferation. With increasing amounts of phosphorylated/S179D PRL, the ratio results first in normal cell proliferation and then in a degree of cell proliferation sufficient for normal cell replacement concomitant with differentiated function. At the other extreme, high concentrations of S179D PRL result in apoptosis. 


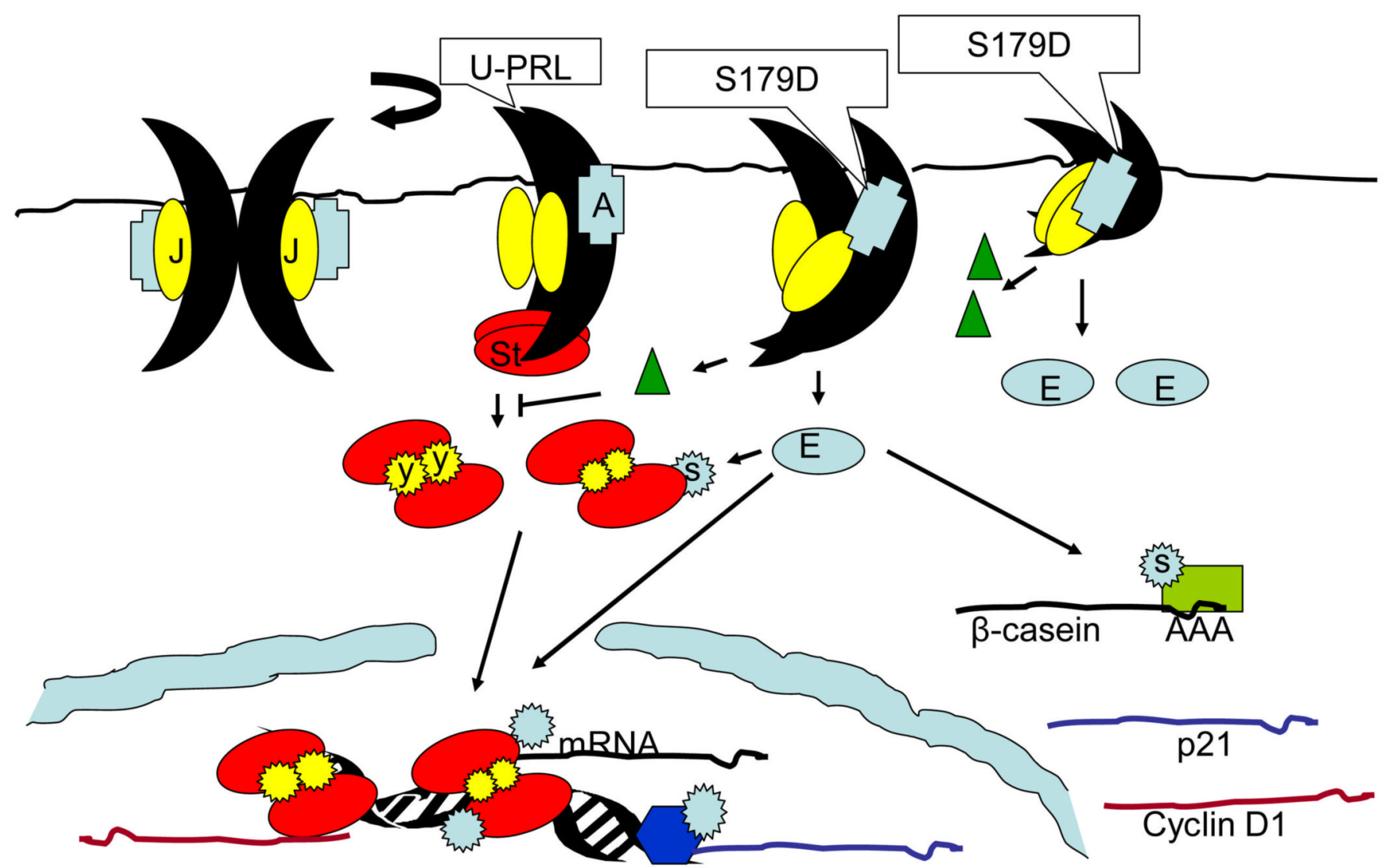

Figure 2. Diagrammatic representation of signaling in response to unmodified PRL and S179D PRL

Panel 1 shows an unliganded long receptor and panel 2 shows the effect of unmodified PRL (U-PRL) at that receptor. Binding of the ligand to the second receptor in the complex, causes a rotation which results in closer proximity of the Jak molecules $(\mathrm{J})$ which then transphosphorylate and phosphorylate the receptor. This recruits $\mathrm{Stat}(\mathrm{St})$ to the receptor. Tyrosine (Y inside star) phosphorylation of Stat by Jak, releases Stat from the receptor, causes dimerization of Stats and entry into the nucleus where they function as transcription factors. Transcription may be of genes associated with cell proliferation (e.g. cyclin D1) or differentiation (e.g. $\beta$-casein), although the suggestion is being made that with more tyrosine phosphorylation (larger stars), preference is for proliferative genes. Panel 3 shows that S179D PRL interacts with the same receptor, but causes a slightly different conformation of the receptor. This results in a reduction of Stat binding and tyrosine phosphorylation (smaller star), greater activation of an alternate signaling complex (A) leading to ERK (E) activation, and the generation of a molecule (green triangles) that limits Stat tyrosine phosphorylation by receptors occupied by unmodified PRL. ERK activation leads to increased Stat serine (S inside star) phosphorylation, thereby altering which sites on the DNA are utilized (less growth-promoting and more differentiative) and, in the case of $\beta$-casein, increasing half life on DNA and promoter activation. ERK activation also leads to increased stability of $\beta$-casein mRNA, diagrammed as phosphorylation of a protein bound to the poly A tail of the message. Additionally, there are other functions resulting from ERK movement into the nucleus and the phosphorylation of additional transcription factors (dark blue hexagon) which result in increased expression of the 
cell cycle-regulating protein, p21. Panel 4 shows how S179D PRL might interact with a short receptor causing increased activation of ERK and increased generation of the molecules that limit Stat tyrosine phosphorylation in response to unmodified PRL. 